\title{
Drug facilitation of avoidance conditioning as a function of pretraining '
}

BARBARA A. DOTY, NORTH CENTRAL COLLEGE LARRY A. DOTY, NORTHERN ILLINOIS UNIVERSITY

\begin{abstract}
Rats were treated with eserine, amphetamine or saline subsequently to each of 4 blocks of 10 trials on a simple avoidance problem. Ss in each treatment group were pretrained to 1 of 2 criteria on the learning task or received no pretraining. Posttrial eserine treatment improved performance in relation to amount of pretraining and affected untrained Ss most. Amphetamine administration facilitated performance equally among all training groups. Results are interpreted in terms of differential drug involvement in trial-initiated neural processes.
\end{abstract}

\section{Problem}

That eserine administration affects retention has been demonstrated in several recent studies (i.e. Russell, 1961; Bures, Bohdanecky, \& Weiss, 1962; Stratton \& Petrinovich, 1963). In the Bures et al study, administration of eserine within $3 \mathrm{~min}$. after training trials facilitated passive avoidance responses. Stratton and Petrinovich observed similar drug facilitation of Lashley maze learning, and Russell reported eserine inhibition of extinction of CARs. Amphetamine administration prior to training trials has also been observed to facilitate acquisition of avoidances (Keleman \& Bovet, 1961; Hearst \& Whalen, 1963).

These findings have sometimes (McGaugh, 1963) been interpreted in terms of drug facilitation of posttrial perseverating neural processes. A serious detraction to this interpretation is the possibility that drug treatment may instead enhance other processes such as motivation, attention, or simply locomotor activity. One approach to clarification of drug effects on memory storage processes versus effects on motivational or other processes is to pretrain Ss on the the learning task prior to drug treatment. Current evidence for a memory consolidation hypothesis suggests that posttrial consolidation of neural traces is substantially complete within a few hours after learning trials. If eserine or amphetamine affect primarily posttrial neural activity, then treatment with these agents should have no effect on performance of Ss who have already acquired the learning task. Any differences in effects of eserine and amphetamine would also suggest differential involvement of cholinergic and adrenergic systems in mediating retention of avoidance responses. Method

One hundred twenty female rats of Long-Evans stock were randomly assigned to 1 of 3 training groups. Training consisted either of no pretraining of any kind, pretraining to a criterion of 9 out of 10 con- secutive avoidances or pretraining to a criterion of 5 out of 10 consecutive avoidances in the apparatus described below. Pretraining procedures were identical to learning procedures described below. To equate pretraining experience, Ss who did not reach either criterion within 40 trials were discarded.

The $40 \mathrm{Ss}$ in each training group were randomly assigned to 1 of 4 treatment groups and received either no treatment of any kind, or I.P. injections of $\mathbf{1 . 5}$ $\mathrm{cc} / \mathrm{kg}$ body weight physiological saline, $0.5 \mathrm{mg} / \mathrm{kg}$ eserine (physostigmine salycilate U.S.P.), or $2 \mathrm{mg} / \mathrm{kg}$ body weight amphetamine sulfate $3 \mathrm{~min}$. after each block of 10 trials on each of 4 consecutive days. Apparatus

Apparatus consisted of a test chamber 29-1/2 by 17 by $4-1 / 2$ in high mounted on a grid charged by a separate power supply which delivered a foot shock intensity of $2.0 \mathrm{ma} \mathrm{A.C}$. current through a shock scramble. The chamber was divided by sliding Plexiglas doors into two end compartments $10-1 / 2$ by $8-1 / 2$ by $4-1 / 2$ in on either side of a center compartment $8-1 / 2$ by 17 by $4-1 / 2$ in. Each end compartment, which served as both start area and avoidance chamber, was equipped with a 5-w incandescent bulb.

\section{Procedure}

All Ss received 10 trials daily for 4 consecutive days. $S$ was placed in one compartment for $10 \mathrm{sec}$. after which lights in both opposite compartments were turned on and served as the CS. Simultaneously, the Plexiglas screen was raised, allowing $S$ to respond. Five sec. later, the US, shock to the feet, was presented unless $S$ had entered either of the opposite compartments. Both CS and US were terminated when S entered a lighted compartment, or $10 \mathrm{sec}$. after US onset. Entry of a lighted compartment prior to shock presentation constituted avoidance.

\section{Results}

A 3 by 4 factorial analysis of variance yielded significant values of $F$ for training $(F=4.60, d f=2 / 108, p<.05)$, treatment $(F=15.94, \mathrm{df}=3 / 108, \mathrm{p}<.01)$, and for the training by treatment interaction $(F=11.83, \mathrm{df}=6 / 108$, $\mathrm{p}<.01$ ). Duncan Multiple Range Tests were used to determine which group means differed signficantly. Mean avoidances performed by all Ss are presented in Table 1.

As might be expected, pretrained Ss in most treatment groups performed at a superior level to Ss lacking such training. Mean avoidances performed by untreated and saline-treated Ss did not differ suggesting that injection 


\section{TABLE I}

Mean Avoidances Performed by All Subjects

Training

\begin{tabular}{lccc}
\hline Treatment & Pretraining 1 & Pretraining 2 & No Pretraining \\
\hline eserine & $25.4^{d}$ & $30.2^{b}$ & $35.4^{b, c}$ \\
saline & $24.2^{d}$ & $20.3^{b}$ & $16.4^{b}$ \\
amphetamine & $33.7^{a}$ & $29.4^{b}$ & $33.4^{b}$ \\
no treatment & $22.0^{d}$ & 18.6 & 15.3 \\
\hline
\end{tabular}

$a_{\text {significantly larger than other column means }(p<.01)}$

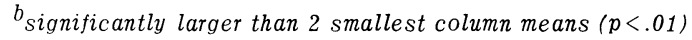

${ }^{c}$ significantly larger than smallest row mean $(p<.01)$

$d_{\text {significantly larger than smallest row mean }(p \subset .05)}$

procedures per se did not affect performance. Both eserine and amphetamine treatment significantly facilitated avoidance performance. While amphetamine administration improved performance equally across training groups, eserine facilitation of performance of untrained Ss was significantly greater $(p<.01)$ than drug effects on Ss pretrained to a criterion of 9 out of 10 consecutive avoidances. Eserine effects on the Ss pretrained to a criterion of 5 out of 10 consecutive avoidances was intermediate between effects on the other two training groups.

\section{Diseussion}

The findings for eserine are in agreement with those of Bures et al (1962), and Stratton \& Petrinovich (1963), indicating that posttrial eserine treatment facilitates avoidance performance. One interpretation of this finding is that eserine acted on posttrial perseverative neural processes. Explanation within this framework would suggest that pretrained Ss were less affected by eserine administration because neural consolidation for them was already complete. However, it is also possible that eserine-produced alterations in motivational or other processes also varied with pretraining, and accounted for facilitating effects of eserine.

The latter interpretation is somewhat weakened by the fact that cholinesterase inhibition by eserine in vivo in mammals is estimated as up to $6 \mathrm{hr}$. (Sollman, 1957; p. 425). In the present study, eserine was administered immediately after trial blocks spaced $24 \mathrm{hr}$. apart. Therefore, a basis of observed drug effects on behavior may be cholinesterase involvement in posttrial neural processes. The hypothesis that the acetylecholinesterase system plays a role in memory storage has been advanced by Rosenzweig et al (1960).

The finding that posttrial amphetamine administration facilitates performance regardless of amount of pretraining suggests that this drug exerts its behavioral effects through a different mechanism of action from that of eserine. It is possible that amphetamine administration elevates motivational or attentional processes in addition to, or instead of, acting on memory storage processes. An analysis of response latencies revealed no significant differences in running speed among any treatment or training groups, suggesting that drug effects on motor aspects of behavior could not account for the variations among treatment groups in avoidance performance.

Whatever the basis of these findings may be, the observed effects of eserine on avoidance performance suggest that the variable of pretraining must be considered in an analysis of drug effects on behavior.

\section{References}

Bures, J., Bohdanecky, Z., \& Weiss, T. Physostigmine induced hippocampal theta activity and learning in rats. Psychopharmacologia, Berlin, 1962, 3, 254-263.

Hearst, E., \& Whalen, R. Facilitating effects of d-amphetamine on discriminated-avoidance performance. J.comp. physiol. Psychol., 1963, 56, 124-128.

Kelemen, K., \& Bovet, D. Effects of drugs upon the defensive behavior of rats. Acta physiol. Acad. Sci. Hung., 1961 19, 143154.

McGaugh, J. L. Neural "Efficiency" and the adaptiveness of behavior.. Symposium paper, XVII International Congress of Psychology, Washington, D.C.; 1963.

Rosenzweig, M. R., Krech, D., \& Bennett, E. L. A search for relations between brain chemistry and behavior. Psychol. Bull. $1960,57,476-491$.

Russell, R. W., Watson, R. H., \& Frankenhaeuser, M. Effects of chronic reductions in brain cholinesterase activity on acquisition and extinction of a conditioned avoidance response. Scand. J. Psychol., Stockholm, 1961, 2, 21-29.

Sollman, T. H. A manual of pharmacology. Philadelphia: W. B. Saunders, Co., 1957.

Stratton, L. O., \& Petrinovich, L. Post-trial injections of an anticholinesterase drug on maze learning in two strains of rats. Psychopharmacologia, Berlin, 1963, 5, 47-54.

\section{Note}

1. Supported in part by NSF grant GE-3943. 